\title{
Redox Electrocatalysis of Floating Nanoparticles: Determining Electrocatalytic Properties without the Influence of Solid Supports
}

\author{
Pekka Peljo, ${ }^{* \dagger \odot}$ Micheál D. Scanlon, ${ }^{\ddagger}{ }^{\dagger}$ Astrid J. Olaya, ${ }^{\dagger}{ }^{\dagger}$ Lucie Rivier, ${ }^{\dagger}$ Evgeny Smirnov, ${ }^{\dagger}$ \\ and Hubert H. Girault ${ }^{*}+{ }^{\dagger}$
†Laboratoire d'Electrochimie Physique et Analytique (LEPA), École Polytechnique Fédérale de Lausanne (EPFL), Rue de l’Industrie 17, CH-1951 Sion, Switzerland
${ }^{\ddagger}$ Bernal Institute and Department of Chemical Sciences, School of Natural Sciences, University of Limerick (UL), Limerick V94 T9PX, Ireland

\begin{abstract}
Redox electrocatalysis (catalysis of electron-transfer reactions by floating conductive particles) is discussed from the point-of-view of Fermi level equilibration, and an overall theoretical framework is given. Examples of redox electrocatalysis in solution, in bipolar configuration, and at liquid-liquid interfaces are provided, highlighting that bipolar and liquid-liquid interfacial systems allow the study of the electrocatalytic properties of particles without effects from the support, but only liquid-liquid interfaces allow measurement of the electrocatalytic current directly. Additionally, photoinduced redox electrocatalysis will be of interest, for example, to achieve water splitting.
\end{abstract}

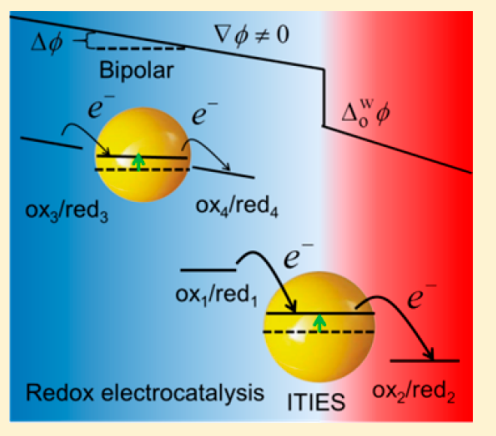

$\mathrm{E}$ lectrocatalysis plays a major role in the development of electrochemical energy storage systems, electrolyzers for hydrogen production, fuel cells, and so forth. ${ }^{1-4}$ The key reactions in such systems, such as hydrogen evolution, oxygen reduction, and water oxidation, are multielectron inner-sphere charge-transfer reactions where metal-molecule interactions are crucial. At the laboratory level, it is relatively easy to prepare well-defined surfaces, for example, $\mathrm{Pt}(111)$, to gather structure-reactivity relationships, but this information is difficult to apply to industrial electrodes. ${ }^{5-7}$ With the rapid development of controlled preparation techniques of metallic nanoparticles (NPs) over the last couple of decades, electrocatalysis often takes place on carbon-supported NPs. ${ }^{5}$ In this case, the activity can be strongly influenced by interactions with the catalyst support. ${ }^{1,2,4}$

\section{The key reactions in electro- chemical energy storage systems are multielectron inner-sphere charge-transfer reactions where metal-molecule interactions are crucial.}

Recently, we have extensively studied charge-transfer reactions on metallic NPs from the point-of-view of Fermi level equilibration. ${ }^{8-12}$ We believe that the concept of Fermi level equilibration between redox species and NPs in solution is key to understand charge-transfer kinetics and thermodynamics of redox electrocatalysis. Therefore, the purpose of this Perspective is to approach charge-transfer events catalyzed by conductive particles, with a primary focus on floating particles. First, a short introduction covering the key definitions and notations will be given, followed by examples of different applications. For a more detailed description, the reader is encouraged to consult refs 8 and 9 .

In brief, the Fermi level of an electron in a redox couple in solution $E_{\mathrm{F}}^{\mathrm{S}}$ is the electrochemical potential of an electron in that redox couple. This is the work to bring an electron from vacuum (taken as zero energy) onto the redox couple in the solution (negative energy). By definition, this is the energy level where the probability of finding an electron is exactly $1 / 2$. The principle is the same as that for the Fermi level of an electron in metals or semiconductors. In the case of metals, if the metal is uncharged, the electrochemical potential is equal in magnitude to the work function, which is the work to remove an electron from a metal bearing no excess charge into the vacuum. The electrochemical potential of the electron in solution can be defined with the aid of a virtual redox reaction between the redox couple $(\mathrm{ox} / \mathrm{red})$ in the solution $\mathrm{S}: \mathrm{ox}^{\mathrm{S}}+\mathrm{e}^{-, \mathrm{S}} \rightleftharpoons \mathrm{red}^{\mathrm{S}}$. Hence, the electrochemical potential of an electron in the solution can be defined as the difference between the electrochemical potentials of the oxidized and reduced species: $\tilde{\mu}_{\mathrm{e}^{-}}^{\mathrm{S}}=\tilde{\mu}_{\mathrm{red}}^{\mathrm{S}}-\tilde{\mu}_{\mathrm{ox}}^{\mathrm{S}}$

It should be noted that the Fermi level of an electron in a redox couple in a solution does not correspond to any molecular orbital. In solution, the energy of an electron in reduced and oxidized states of the redox couple fluctuates due

Received: March 23, 2017

Accepted: July 14, 2017

Published: July 14, 2017 
to changes in the solvation. Generally, this fluctuation is described by a Gaussian distribution with the width depending on the solvent reorganization energy from Marcus theory. The energy distributions around an average value are due to temporal fluctuations due to changes in solvation, and they do not represent band levels like in a solid. ${ }^{13}$ For further discussion about the concept of the Fermi level of electron in solution, see, for example, the review of Reiss. ${ }^{14}$

\section{We believe that the concept of Fermi level equilibration between redox species and NPs in solution is key to understand charge- transfer kinetics and thermody- namics of redox electrocatalysis.}

On the other hand, by analogy with the Nernst equation, the standard redox potential of the redox reaction with an electron at rest in vacuum ox ${ }^{\mathrm{S}}+\mathrm{e}^{-, \mathrm{V}} \rightleftharpoons \mathrm{red}^{\mathrm{S}}$ is simply $\mathrm{e}\left[E_{\mathrm{ox} / \mathrm{red}}^{\ominus}\right]_{\mathrm{AVS}}^{\mathrm{S}}=$ $-\Delta G_{\text {red }}^{\ominus}=\mu_{\text {ox }}^{\ominus, \mathrm{S}}-\mu_{\text {red }}^{\ominus, \mathrm{S}}$, where AVS refers to the absolute vacuum scale $\left(\left[E_{\mathrm{SHE}}^{\ominus}\right]_{\mathrm{AVS}}^{\mathrm{aq}}=4.44 \mathrm{~V}\right)$ and the superscript $\ominus$ refers to the standard state. Finally, the Fermi level of the electron in solution can be defined as $E_{\mathrm{F}, \mathrm{s} / \mathrm{red}}^{\mathrm{S}}=-\mathrm{e}\left[E_{\mathrm{ox} / \mathrm{red}}\right]_{\mathrm{AVS}}^{\mathrm{S}}-\mathrm{e} \phi^{\mathrm{S}}=\tilde{\mu}_{\mathrm{e}^{-}}^{\mathrm{S}}$, where $\phi^{S}=\psi^{S}+\chi^{S}$ is the Galvani potential of the phase $S$, composed of the inner potential $\chi^{S}$ and outer potential $\psi^{S} .9$ If there is no surface charge, the outer potential of the phase is $\psi^{S}$ $=0$, and the electrochemical potential $\tilde{\mu}$ is equal to the real chemical potential $\alpha, \tilde{\mu}_{\mathrm{e}^{-}}^{\mathrm{S}}=\mu_{\mathrm{e}^{-}}^{\mathrm{S}}-\mathrm{e} \phi^{\mathrm{S}}=\mu_{\mathrm{e}^{-}}^{\mathrm{S}}-\mathrm{e}\left(\chi^{\mathrm{S}}+\psi^{\mathrm{S}}\right)=\alpha_{\mathrm{e}^{-}}^{\mathrm{S}}-$ $\mathrm{e} \psi^{\mathrm{S}}$. The real chemical potential of an electron is the work to bring the electron into an uncharged phase, and it is the negative of the work function of the phase, $\alpha_{\mathrm{e}^{-}}=-\Phi$. If there is more than one redox species in solution, their Fermi levels are all equal at equilibrium.

Electrocatalysis is a process where rates of electron-transfer reactions are increased by the electrode material itself or by deposition of the catalyst on the surface (heterogeneous catalysis) or addition of the catalyst into the solution (so-called "homogeneous catalysis" or redox catalysis). Most commonly, catalyst particles are deposited on the electrode surface to obtain NP-modified electrodes. Now, the key aspect of these electrodes is that the Fermi level of the metal NP $E_{\mathrm{F}}^{\mathrm{NP}}$ equilibrates with the Fermi level of the electrode, controlled by an external power source, as shown in Figure 1a.

Redox catalysis can be defined as homogeneous catalysis of electron-transfer reactions between two species in solution; this process can be also considered as Fermi level equilibration between electrons in the two redox couples. ${ }^{8}$ Most enzymes actually function as redox catalysts by catalyzing the electron transfer, for example, between glucose and oxygen (Figure 1b). Of course, the situation is more complex than described above, involving many different steps, but Figure $1 \mathrm{~b}$ shows the simplified process. Additionally, enzymes can be immobilized on electrode surfaces to undergo direct or mediated electron transfer with the electrode in bioelectrocatalysis. ${ }^{15}$ Bioelectrocatalysis can be considered as a subdiscipline of electrocatalysis, both fields sharing many similarities, as highlighted in a recent review. ${ }^{15}$

In this Perspective, we mainly focus on redox electrocatalysis, that is, the catalysis of electron transfer reactions between two species in solution by conductive catalyst particles, as described in Figure 1c. For simplicity, we limit the discussion only to
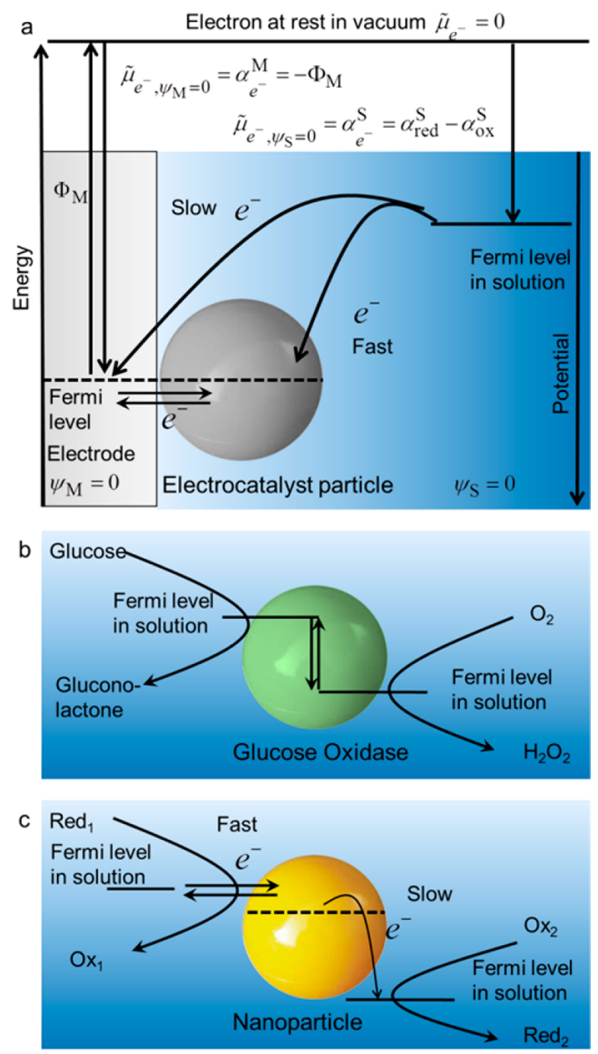

Figure 1. (a) Energy diagram for electrocatalysis (or bioelectrocatalysis if the catalyst is an enzyme and so forth. (b) Redox catalysis of glucose oxidation by oxygen with a glucose oxidase enzyme (simplification). (c) Redox electrocatalysis of electron transfer through a conductive floating electrocatalyst particle.

conductive particles. However, the principles in this Perspective apply also for semiconductor nanocrystals and quantum dots, where the zone structure and size-dependent band energy need to be taken into account. These systems have been discussed in detail elsewhere. ${ }^{16-18}$

Let us first discuss the concept of Fermi level equilibration of a metallic NP when more than one redox couple is present in the surrounding solution, imposing conditions that none of the redox couples are in excess dominating the redox potential in solution and the metallic NP itself is completely chemically inert. Specifically, we consider the scenario when a metallic NP acts as an electron mediator, essentially shuttling electrons from a donor redox couple $\mathrm{ox}_{1} / \mathrm{red}_{1}$ to a second acceptor redox couple $\mathrm{ox}_{2} / \mathrm{red}_{2}$ via the metallic NP. Note that the system is not in equilibrium due to the kinetic limitations of the direct homogeneous electron transfer. The NP catalyzes electron transfer, and the $E_{\mathrm{F}}^{\mathrm{NP}}$ will be controlled by the rates of the two redox reactions. ${ }^{9}$ When equilibrium has finally been reached, there are no concentration gradients and the $E_{\mathrm{F}}^{\mathrm{NP}}$ is determined by the equilibrium potential of reaction 1 .

$$
\mathrm{red}_{1}+\mathrm{ox}_{2} \stackrel{\text { metallic NP }}{\longrightarrow} \mathrm{ox}_{1}+\operatorname{red}_{2}
$$

A typical example would be the thermodynamically feasible but kinetically sluggish reaction between $\mathrm{V}^{2+}$ ions and protons in acid solution. ${ }^{19-21}$ Indeed, acidic $\mathrm{V}^{2+}$ solution generally employed in vanadium redox flow batteries is stable for months and years even though thermodynamically it should be oxidized to evolve hydrogen. The standard redox potential for the $\mathrm{V}^{2+}$ / $\mathrm{V}^{3+}$ redox couple is equal to $-0.255 \mathrm{~V}$ (vs SHE), being more 
negative than that for $\mathrm{H}^{+} / \mathrm{H}_{2}$ equal to $0.0 \mathrm{~V}$ (vs SHE) at $\mathrm{pH} 0$. Hence, under anaerobic conditions, this reaction should be spontaneous. ${ }^{19-21}$ The Galvani potential in aqueous phase can be assumed constant; therefore, the Fermi level difference is equal to the Nernst potential difference. However, the equilibration is very slow due to the slow kinetics of the $\mathrm{H}_{2}$ evolution reaction (HER) in the absence of a catalyst. Addition of catalytic NPs enables oxidation of $\mathrm{V}^{2+}$ and $\mathrm{H}_{2}$ evolution, equilibrating the Fermi levels of the electron in solution for the redox couples and that of the electron on the metallic particles. ${ }^{19-21}$

The position of the $E_{\mathrm{F}}^{\mathrm{NP}}$ in the catalyst particle depends on the rates of the electron-transfer reactions on the catalyst surface. ${ }^{9}$ This is illustrated qualitatively in Figure 2. When both reactions require a similar driving force, the $E_{\mathrm{F}}^{\mathrm{NP}}$ will reach a quasi-steady state in the middle of the Fermi levels of electrons in the two reacting species. If the exchange current density $i_{0}$ for one of the reactions is significantly higher than the other, the slower reaction requires more overpotential and the quasi-

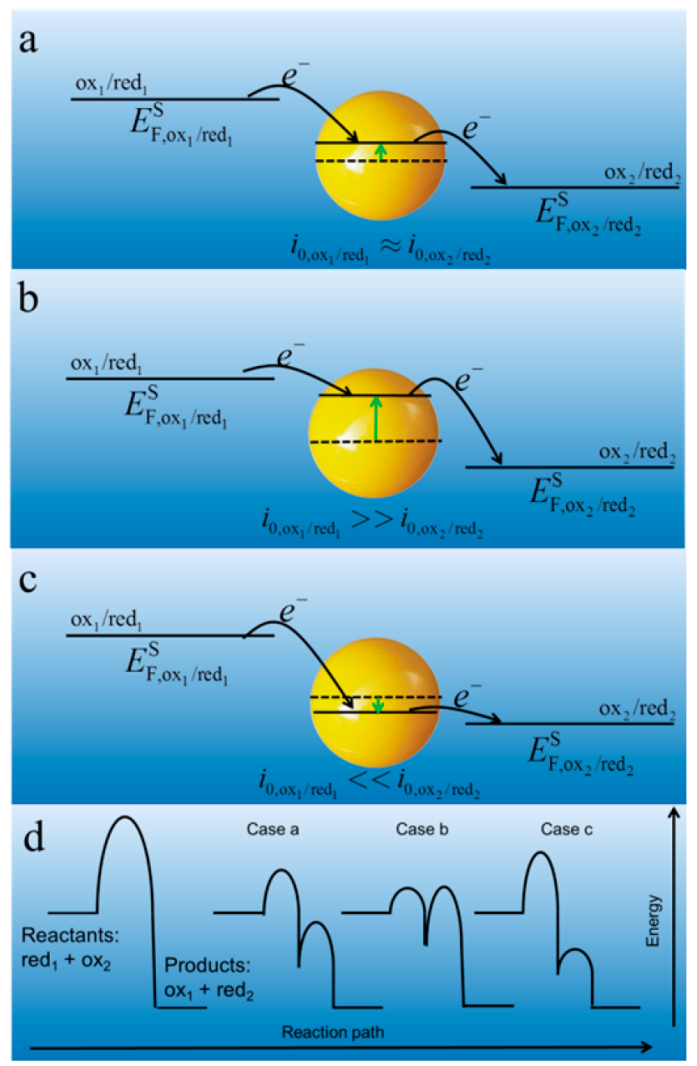

Figure 2. Fermi level equilibration of a metallic NP with more than one redox couple present in solution in similar concentrations. The metallic NP acts as a mediator, shuttling electrons between electrocatalyzed oxidation and reduction half-reactions during redox electrocatalysis. The kinetics of the two half-reactions determine the final position of $E^{\mathrm{NP}}$ if neither redox couple is in excess, with three ideal scenarios depicted when (a) both reduction and oxidation rates are equal, (b) oxidation is much faster, and (c) the oxidation reaction is limiting. This scheme is valid under conditions where concentration polarization at the surface of the metallic NP is negligible and the metallic NP is chemically inert in solution (i.e., it does not dissolve when oxidized). (d) Schematic illustration of energy diagrams for the noncatalyzed reaction and for redox electrocatalysis in cases a, b, and c, showing the middle state where electron transfer from red $_{1}$ to the NP has taken place. steady state $E_{\mathrm{F}}^{\mathrm{NP}}$ will equilibrate close to the Fermi level of the faster redox couple, as shown in Figure 2b,c. The situation can be illustrated considering Butler-Volmer kinetics for both oxidation and reduction. For simplicity, backward reactions are neglected (i.e., overpotentials for both reactions are large enough that backward components are negligible) Taking all of these points into consideration, the equilibrium condition can be expressed as

$$
\begin{aligned}
I_{\text {ox }} & =A_{\text {ox }} i_{0, \text { ox }}\left(c_{\text {red }_{1}}^{\mathrm{S}} / c_{\text {red }_{1}}^{*}\right) \mathrm{e}^{\beta_{\text {ox }} n_{\mathrm{ox}} f \eta_{\text {ox }}}=-I_{\text {red }} \\
& =-A_{\text {ox }} i_{0, \text { red }}\left(c_{\mathrm{ox}_{2}}^{\mathrm{S}} / c_{\mathrm{ox}_{2}}^{*}\right) \mathrm{e}^{\left(\beta_{\text {red }}-1\right) n_{\text {red }} f \eta_{\text {red }}}
\end{aligned}
$$

where subscript ox refers to the oxidation reaction of $\operatorname{red}_{1}$ to $\mathrm{ox}_{1}$, subscript red to the reduction reaction of $\mathrm{ox}_{2}$ to $\operatorname{red}_{2}$, superscript $S$ refers to the surface concentration and * to the bulk value, $I$ is the current, $A$ is the area available for the reaction, $n$ is the number of electrons (for simplicity considered as 1$), i_{0}=n F k^{0}\left(c_{\mathrm{ox}}^{*}\right)^{\beta}\left(c_{\text {red }}^{*}\right)^{1-\beta}$ is the exchange current density, $f=$ $F / R T, \beta$ is the charge-transfer coefficient (here symbol $\beta$, generally estimated as 0.5 , is used instead of typical $\alpha$ to avoid confusion with the real chemical potential), and $\eta=E-E_{\text {eq }}$ is the overpotential, that is, the driving force for the electrontransfer reaction between the NP and the redox couple expressed in volts. Equaiton 2 can be written also in terms of Femi levels, as demonstrated in ref 9. In this case, the driving force is the difference of the Fermi levels of the NP and the redox couple in solution, expressed in eVs. For simplicity, if the concentration polarization is ignored $\left(c^{S} \approx c^{*}\right)$, the potential of the NP can be expressed as

$$
E=\frac{\left(E_{\mathrm{eq}, \mathrm{ox}}+E_{\mathrm{eq}, \mathrm{red}}\right)}{2}+\frac{R T}{F} \ln \left(\frac{A_{\mathrm{red}} i_{0, \mathrm{red}}}{A_{\mathrm{ox}} i_{0, \mathrm{ox}}}\right)
$$

or in terms of Fermi levels, if the Galvani potentials are neglected

$$
E_{\mathrm{F}}^{\mathrm{NP}}=\frac{\left(E_{\mathrm{F}, \mathrm{ox}_{1} / \mathrm{red}_{1}}+E_{\mathrm{F}, \mathrm{ox}_{2} / \mathrm{red}_{2}}\right)}{2}-k T \ln \left(\frac{A_{\mathrm{red}} i_{0, \mathrm{red}}}{A_{\mathrm{ox}} i_{0, \mathrm{ox}}}\right)
$$

This equation shows that when the areas available for both reactions are the same, if $i_{0 \text {,red }} \approx i_{0, \text { ox }}$, the Fermi level of the NP will be the average of the two redox couples (Figure 2a). If $i_{0, \text { red }}$ $\gg i_{0, \text { ox }}$, the Fermi level of the NP will equilibrate close to the Fermi level of the $E_{\mathrm{F}, \mathrm{ox}_{2} / \mathrm{red}_{2}}$, as illustrated in Figure $2 \mathrm{c}$, and if $i_{0, \text { red }} \ll i_{0, \mathrm{ox}}$ the Fermi level of the NP will equilibrate close to the Fermi level of the $E_{\mathrm{F}, \mathrm{ox}_{1} / \mathrm{red}_{1}}$, as in Figure $2 \mathrm{~b}$. The Fermi level of the NP is of course limited between the $E_{\mathrm{F}, \mathrm{ox}_{1} / \mathrm{red}_{1}}$ and $E_{\mathrm{F}, \mathrm{ox}_{2} / \mathrm{red}_{2}}$.

The energy diagram of the reaction path is illustrated in Figure $2 \mathrm{~d}$. Now there exists a middle state where electron transfer between one couple and the NP has occurred. Figure $2 \mathrm{~d}$ illustrates the cases where electron transfer from red $_{1}$ to the NP takes place first. However, the opposite order, that is, electron transfer from NP to $\mathrm{ox}_{2}$ followed by electron transfer to NP from red $_{1}$, can in some cases be more likely, especially if this reaction is easier.

Theoretical treatment of redox electrocatalysis in a single phase was first proposed by Spiro ${ }^{22}$ and Bard. ${ }^{23}$ We have recently extended the theory to consider also electron-transfer reactions between redox couples dissolved in immiscible liquid phases, catalyzed by conductive particles adsorbed at the liquid-liquid interface. 9 This reasoning, where two or more 
distinct half-reactions combine to establish a potential with a net zero external current, a so-called mixed potential, was first described by Wagner and Traud. ${ }^{24,25}$ The concept of the mixed potential has largely been used in corrosion science, ${ }^{26}$ electrodeless deposition, ${ }^{27}$ and catalytic systems involving metal catalysis of solution redox reactions. ${ }^{22,28}$

Examples of redox electrocatalysis date back to the pioneering works of the groups of Henglein, Miesel, Grätzel, Bard, and others in late 1970s. Their works involved generating organic and inorganic free radicals in deaerated aqueous solutions to charge and discharge colloidal metallic NPs predominantly of $\mathrm{Pt}^{29-33} \mathrm{Ag}^{28,34-36}$ and $\mathrm{Au}^{37-39}$ Free radicals may be generated radiolytically via exposure of a mixture of 2propanol and acetone to $\gamma$-irradiation from a ${ }^{60} \mathrm{Co}$ source ${ }^{34}$ or with UV light. ${ }^{36}$ Radicals could also be produced photochemically via excitation of $\mathrm{Ru}(\mathrm{bpy})_{3}{ }^{2+}$ in solution with methylviologen dications $\left(\mathrm{MV}^{2+}\right)$ as the electron acceptor with a sacrificial electron donor ${ }^{23,31}$ or by electrochemical reduction of $\mathrm{MV}^{2+} .^{23}$ The variously generated free radicals diffuse toward the floating metallic NPs in solution and may transfer multiple electrons or inject holes and thereby raise or lower $E_{\mathrm{F}}^{\mathrm{NP}}$, respectively. The resultant negatively or positively charged metallic NPs are effectively polarized floating "microelectrodes" or "nanoelectrodes". 40,41

Such floating nanoelectrodes are redox electrocatalysts capable of facilitating redox reactions that would otherwise be extremely slow or impossible due to kinetically rapid competing deactivation processes of the free radicals, that is, radical recombination, disproportionation, or dismutation. ${ }^{34}$ The bulk of the initial studies involved charged metallic NPs catalyzing the HER in the presence of continuously generated free radicals. ${ }^{23,28-33,36-38}$ Some other multielectron transfer redox reactions were also explored that were kinetically competitive with the HER on Ag NPs, such as the reduction of $\mathrm{N}_{2} \mathrm{O}, \mathrm{NO}_{3}{ }^{-}$, $\mathrm{Cd}^{2+}, \mathrm{Tl}^{+}$, and $\mathrm{CH}_{2} \mathrm{Cl}_{2}{ }^{42,43}$ Negatively polarized metallic NPs may also be used to reduce the ions of different metals in solution to produce core-shell bi- or even trimetallic NPs. Thus far, numerous bimetallic core-shell combinations have been produced with homogeneous films of cadmium, ${ }^{44}$ lead and indium, ${ }^{45}$ gold, ${ }^{46}$ and mercury ${ }^{47,48}$ grown around Ag NP cores and homogeneous films of tin, thallium, cadmium, and $\mathrm{Pb}$ grown around Au NP cores. ${ }^{49,50}$ A trimetallic material consisting of a $\mathrm{Au} \mathrm{NP}$ core, with a $\mathrm{Pb}$ mantle and $\mathrm{Cd}$ exterior has also been prepared using this strategy. ${ }^{51}$

Clearly, the equilibration position of the $E_{\mathrm{F}}^{\mathrm{NP}}$ strongly depends on the nature of the NP. $\mathrm{Au}$ and Ag NPs, for example, behave as "reservoirs of electrons" due to their relatively high overpotentials for evolving $\mathrm{H}_{2}$ (the scenario depicted in Figure 2b). ${ }^{28,29}$ The rate of electron injection is diffusion-limited, and thus, $\mathrm{Au}$ and $\mathrm{Ag}$ NPs are capacitive in nature due to a strong buildup of stored charge. Indeed, during continuous free radical generation, Ag NPs build up a stationary rise in $E_{\mathrm{F}}^{\mathrm{NP}}$ of as much as $1 \mathrm{~V}$. Conversely, Pt NPs act as "reservoirs of adsorbed hydrogen atoms or holes" under otherwise identical experimental conditions due to their low overpotential to evolve $\mathrm{H}_{2}{ }^{29}$ Therefore, Pt NPs are described as ohmic in nature, in a sense that hydrogen evolution takes place as fast as the free radicals are able to inject electrons into the metal, and $E_{\mathrm{F}}^{\mathrm{NP}}$ is pinned to the reduction potential of protons in the aqueous phase (the scenario depicted in Figure 2c).

Let us now consider floating catalytic rafts, where electrocatalytic metallic NPs are immobilized on a floating conductive support, as illustrated in Figure 3. If the oxidation reaction takes place both on the floating support and on the metallic NP but
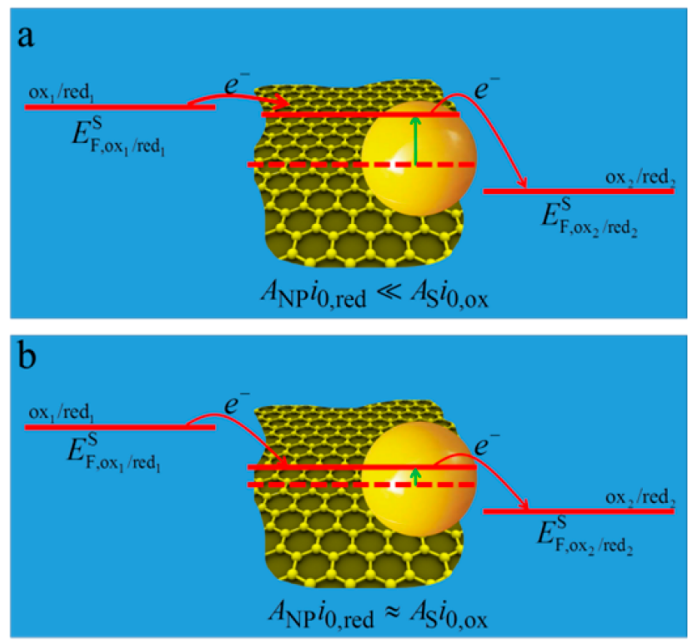

Figure 3. Fermi level equilibration of a metallic NP immobilized on a carbon support, graphene in this case, with two redox couples present in solution. The oxidation of $\mathrm{ox}_{1} / \mathrm{red}_{1}$ can occur both on the carbon support and directly at the surface of the metallic NP. However, the reduction of $\mathrm{ox}_{2} / \mathrm{red}_{2}$ only occurs efficiently at the surface of the metallic NP. The huge difference in electroactive areas for the two half-reactions dramatically affects the equilibration position of $E_{\mathrm{F}}^{\mathrm{NP}}$ and the overpotential for the reduction of $\mathrm{ox}_{2} / \mathrm{red}_{2}$ during redox catalysis. Two ideal scenarios are depicted when (a) exchange current densities for both reactions are similar and (b) exchange current density is higher for the reduction of $\mathrm{ox}_{2} / \mathrm{red}_{2}$. In this case, the available surface area of the NPs limits the reduction reaction; therefore, the difference in the required overpotentials is compensated by the difference in the available surface area for the reaction. This scheme is valid under conditions where concentration polarization at the surface of the metallic NP is negligible, neither redox couple is in excess, and the metallic NP is chemically inert in solution.

the reduction has very slow kinetics on the support, at equilibrium, the current for both reactions has to be the same. For example, in the case of the HER catalyzed by Pt NPs on a carbon support, the support is inactive toward the HER. Nonetheless, the support can readily accept electrons from a donor redox couple in solution, as illustrated in Figure 3. Thus, the electroactive area for the oxidation reaction is the total area of the support and the metallic NPs, $A_{\text {tot }}$.

Meanwhile, the electroactive area for the reduction reaction remains only the area of the metallic NPs, $A_{\mathrm{NP}}$. Usually, the area of the support, $A_{\mathrm{S}}$, is much higher than the area of the metallic NPs, and hence, $A_{\text {tot }} \approx A_{\mathrm{S}}$. If the exchange current densities for both the oxidation and reduction reactions are similar, the overpotential needed to drive the reduction reaction will be much higher than that for the case of a "freely diffusing" metallic NP as the active area for oxidation reaction is higher than the active area for reduction. This can be justified by writing eq 4 for the floating catalytic raft as follows:

$$
E_{\mathrm{F}}^{\mathrm{NP}}=\frac{\left(E_{\mathrm{F}, \mathrm{ox}_{1} / \mathrm{red}_{1}}+E_{\mathrm{F}, \mathrm{ox}_{2} / \mathrm{red}_{2}}\right)}{2}-k T \ln \left(\frac{A_{\mathrm{NP}} i_{0, \mathrm{red}}}{A_{\mathrm{S}} i_{0, \mathrm{ox}}}\right)
$$

In this case, $A_{\mathrm{NP}} i_{0, \text { red }} \ll A_{\mathrm{S}} i_{0, \mathrm{ox}}$ because $A_{\mathrm{NP}} \ll A_{\mathrm{S}}$ and $E_{\mathrm{F}}^{\mathrm{NP}}$ will equilibrate close to $E_{\mathrm{F}, \mathrm{ox}_{1} / \mathrm{red}_{1}}^{\mathrm{S}}$. Now, the floating raft will act as an electron reservoir, ensuring that the reduction reaction will have a very high driving force; see Figure 3a. On the other 
hand, if the exchange current density for the oxidation reaction is considerably smaller than the for the reduction, this effect can be compensated by the larger electroactive area of the support (compare the scenarios in Figures $2 \mathrm{c}$ and $3 \mathrm{~b}$ ). For example, if $A_{\mathrm{NP}} i_{0, \text { red }} \approx A_{\mathrm{S}} i_{0, \mathrm{ox}}$, the Fermi level of the NP immobilized on a carbon support will be the average of the two redox couples (Figure 3b). Finally, if $A_{\mathrm{NP}} i_{0, \text { red }} \gg A_{\mathrm{S}} i_{0, \mathrm{ox}}$, the Fermi level of the catalytic raft will equilibrate close to the Fermi level of the $E_{\mathrm{F}, \mathrm{ox}_{2} / \mathrm{red}_{2}}$. The Fermi level of the catalytic raft is of course limited between $E_{\mathrm{F}, \mathrm{ox}_{1} / \mathrm{red}_{1}}$ and $E_{\mathrm{F}, \mathrm{ox}_{2} / \mathrm{red}_{2}}$.

Support can have also additional benefits for redox electrocatalysis. For example, it was observed that $\mathrm{MoS}_{2}$ and $\mathrm{Pt}$ NPs grown on carbon supports ${ }^{52,53}$ (such as carbon nanotubes ${ }^{54}$ or graphene ${ }^{52,53}$ ) act as superior electrocatalysts toward the HER as they provide conductive scaffolds that lead to (i) a significant decrease in the average NP size during synthesis, which increases the number of accessible catalyst edge sites, (ii) an increase of the dispersion of the catalyst, which again maximizes the availability of exposed surface catalytic sites, and (iii) rapid electron transfer between the electron donor and the less conducting $\mathrm{MoS}_{2}$ NPs thanks to the low-resistance transport of the carbon supports (see Figures 3 and $6 \mathrm{e}$ for the mechanism at ITIES).

Of course, when the support is connected to an external voltage source, as is typical in any electrochemical experiment, the Fermi level of the whole system is defined by the applied potential, and hence, this consideration only applies for freely floating systems or systems adsorbed at the interface between two immiscible electrolyte solutions (ITIES, discussed vide infra), which we call floating catalytic rafts.

In real cases, the Fermi level reaches a pseudo-steady-state, with a concentration polarization affecting the Fermi level as the reaction proceeds. For example, in the case of the HER catalyzed by floating carbon-supported Pt NPs in the presence of a donor redox couple $\left(\mathrm{ox}_{1} / \mathrm{red}_{1}\right), E_{\mathrm{F}}^{\mathrm{NP}}$ will depend on the ratio of exchange current densities, the ratio of electroactive surface areas $\left(A_{\mathrm{S}}\right.$ and $\left.A_{\mathrm{NP}}\right)$, and also the surface concentrations of $\mathrm{ox}_{1}, \operatorname{red}_{1}, \mathrm{H}^{+}$, and $\mathrm{H}_{2}$. If we assume that $A_{\mathrm{S}}$ is much larger than $A_{\mathrm{NP}}$, then the $E_{\mathrm{F}}^{\mathrm{NP}}$ will equilibrate close to the equilibrium potential of $\mathrm{ox}_{1} / \operatorname{red}_{1}$ (Fermi level of the solution, $E_{\mathrm{F}, \mathrm{ox}_{1} / \mathrm{red}_{1}}^{\mathrm{S}}$ ). As the reaction proceeds, the surface concentration of $\mathrm{ox}_{1}$ increases, and hence, both $E_{\mathrm{F}, \mathrm{ox}_{1} / \mathrm{red}_{1}}^{\mathrm{S}}$ at the surface and $E_{\mathrm{F}}^{\mathrm{NP}}$ will increase. The whole system reaches equilibrium when $E_{\mathrm{F}, \mathrm{ox}_{1} / \mathrm{red}_{1}}^{\mathrm{S}}$ and $E_{\mathrm{F}, \mathrm{ox}_{2} / \mathrm{red}_{2}}^{\mathrm{S}}$ are equal and all concentration gradients have disappeared.

Recently, single NP electrochemistry has received a considerable amount of attention in the literature. ${ }^{55-59}$ The NPs can undergo charge transfer with the metal electrodes, they can be dissolved at the electrode, or the can electrocatalyze reactions that otherwise are very slow on the electrode substrate. $^{55-59}$ The NPs can either stick to the electrode surface in a perfectly inelastic collision (this approach can be used to monitor adsorption of insulating particles) or "touch and go" in an elastic collision. ${ }^{55-59}$ It is also possible to carry out electrochemical modification of the NPs either by electrodeposition or oxide layer formation. All of these strategies can be employed with nanoscale and microscale electrodes to obtain the electrochemical response of a singleNP collision. ${ }^{55-59}$

In the case of particles sticking to the electrode, the electrode will impose its Fermi level on the NP as the tunneling of electrons between the two is generally faster than the redox reaction at the particle surface, as described in Figure 1a. However, if the colliding particle does not stick to the electrode, there can be charge transfer, but not necessarily enough to equilibrate the Fermi levels. There are still open questions, the most important one being, does the Fermi level equilibration reach equilibrium upon contact? There is no need for physical contact as it is enough for the particle to approach within the electron tunneling distance of the surface to allow charge transfer. ${ }^{59}$ If equilibrium is reached, the particle will start to discharge by electrochemical reaction with the redox couple in solution. If the kinetics of this reaction is rather slow, this process can take some time so that it actually takes place in the bulk. Therefore, in principle, particles could function as electron shuttles between the bulk and the electrode. The diffusion of particles is much slower, but, on the other hand, particles can carry more charge (i.e., a 100 times slower particle could carry 100 times more charge compared to a molecular redox couple); therefore, different behavior can be observed depending on the particle size, electrode potential, convection, redox kinetics, and so forth. For example, if the redox kinetics between the particle and the redox couple are slow, the particle will be charged at the electrode and it will slowly discharge until the Fermi level is equilibrated with the redox couple in solution, as illustrated in Figure 4a. This kind of behavior should be
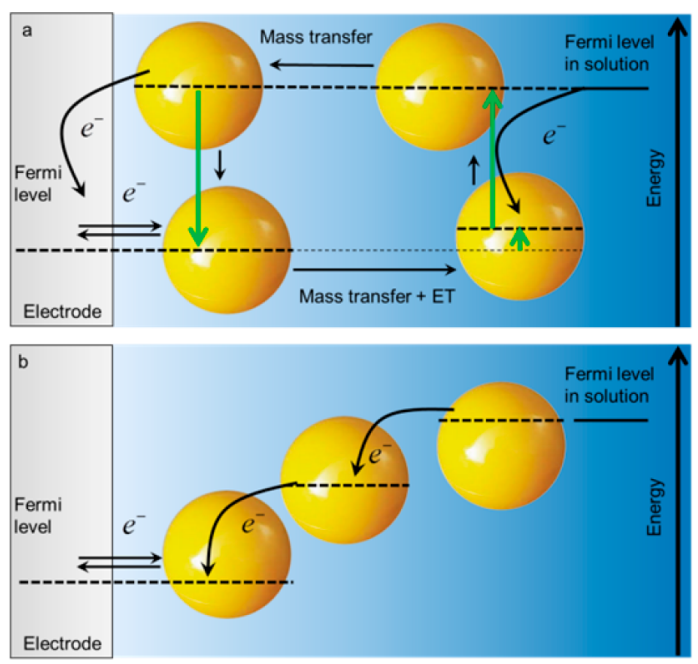

Figure 4. Two primary ways for Fermi level equilibration between a NP in solution and a bulk electrode: (a) "touch-and-go" mechanism for NP impact equilibrating at the electrode followed by slow discharge in the bulk until the Fermi level is equilibrated with the redox couple in the solution and (b) redox electrocatalysis by an electron hopping mechanism.

observable, for example, with some spectroscopic techniques due to changes in the plasmonic spectra of NPs upon charging and discharging. ${ }^{60,61}$ On the other hand, charge transfer events could also take place by electron hopping between the NPs, as described in Figure $4 b$.

In the case of NP dissolution, if the Fermi level of the electrode is insufficient to achieve complete dissolution of the particle due to the increased activity of the dissolved metal ion on the surface of the particle, the particle will initially not completely dissolve. However, when the particle moves away from the electrode, the concentration of the metal ion will slowly relax to the bulk concentration, initiating additional 
dissolution of the particle. Hence, care should be taken when utilizing impact experiments for NP size distribution characterization. However, if the redox potential is sufficiently high, full dissolution of the particle can be achieved upon impact. ${ }^{62}$ This also highlights the importance of the identification of the ratelimiting step. If the concentration of the reacting redox couple is low, there can be a significant buildup of Fermi level gradient (the Fermi level of electrons in solution is directly proportional to the Nernst potential) in the diffusion layer, and mass transfer, not electron transfer kinetics, will limit the reaction rate. We have recently highlighted that the Fermi level of the $\mathrm{NP}$ will also change as the function of the distance from the electrode due to the changing double layer capacitance of the NP. The electric double layer of the electrode perturbs the capacitance of the NP close to the electron surface, and this effect is more pronounced with small NPs in dilute electrolyte solutions. $^{63}$

Bipolar systems are another interesting example of situations where redox electrocatalysis can take place. ${ }^{64-66}$ In this case, conductive particles are suspended in an electrolyte solution between two electrodes, and the equilibrium situation in the absence of the electric field is illustrated in Figure 5a. When current is flowing between the two electrodes, there is a potential drop in solution due to its ohmic resistance. This current flow imposes a Galvani potential gradient into the

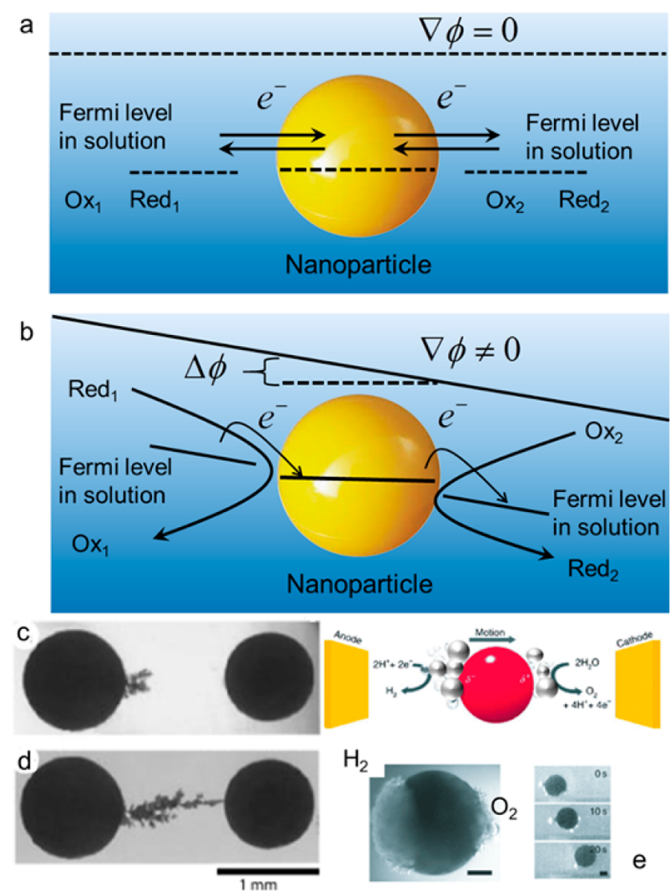

Figure 5. Fermi level equilibration in the external electric field. (a) Particle in equilibrium with the two redox couples in the absence of an electric field. (b) Fermi levels of electrons in the two redox couples in the solution and in the particle immediately after applying an electric field (simplification not considering the double-layer effects). (c,d) Examples of copper particle dissolution on the left and deposition on the right side of the particles under an electric field of $30.3 \mathrm{~V} \cdot \mathrm{cm}^{-1}$ after 10 (c) and $29 \mathrm{~s}(\mathrm{~d})$ of applied potential. Adapted with permission from Macmillan Publishers Ltd., Nature, ref 67, copyright 1997. (e) Bipolar water splitting on a $1 \mathrm{~mm}$ diameter stainless steel bead, showing $\mathrm{O}_{2}$ evolution on the right and $\mathrm{H}_{2}$ evolution on the left. Adapted with permission from Macmillan Publishers Ltd., Nature Communications, ref 68, copyright 2011. cell. ${ }^{64-66}$ As the Fermi level of an electron in solution is directly dependent on the Galvani potential of the solution, there will be also a Fermi level gradient, as shown in Figure 5b. At high enough potential differences (a $10 \mathrm{~nm}$ diameter particle would require a field of $1 \mathrm{MV} \cdot \mathrm{cm}^{-1}$ to generate a potential difference of $1 \mathrm{~V}$ across the particle; in electrochemistry, electric fields are typically $1-10 \mathrm{~V} \cdot \mathrm{cm}^{-1}$, and bipolar electrochemistry of $100 \mu \mathrm{m}$ particles requires fields of $10-1000 \mathrm{~V} \cdot \mathrm{cm}^{-1}$; lower voltages would be required for catalytic rafts that are larger) between the two electrodes, the potential drop in the solution from one end of the particle to the other (Galvani potential difference within the electrolyte solution) can become significant enough to start electrochemical reactions at the surfaces of the particles, conducting current through them instead of migration in the electrolyte solution. ${ }^{65}$ In this case, oxidation takes place at the end of the particle feeling the higher Galvani potential of the solution, and reduction takes place at the other end. If the resistance of a conductor is much smaller than the resistance of an electrolyte solution, potential drop within the conductor is quite small compared to the potential drop within the electrolyte. Hence, the Fermi level of electrons in the conductor is almost constant, while the Fermi level of electrons in solution varies considerably along the conductor. Bipolar reactions can be understood as the conducting particle equilibrating the Fermi levels of the electrolyte in the two positions, in the presence of a strong Galvani potential gradient. Figure 5a shows the particle in equilibrium in the absence of the Galvani potential gradient.

When the current is turned on (Figure $5 b$ ), there is a linear Galvani potential gradient in the solution between the two electrodes providing the current. Now, the current passing through the NP tries to equilibrate the Fermi levels of the two redox couples at opposite ends of the particle, resulting in a nonlinear electric field in the solution above the particle. ${ }^{.5}$ The Fermi levels of the redox couples in the solution are also perturbed by the change of the ratio of ox/red species in solution.

Now, it is important to understand that in many cases the Fermi levels of the two couples need to equilibrate at both ends of the NP. However, this equilibration usually takes place by very slightly changing the concentration of one of the couples. For example, considering a metal particle in acidic solution, metal dissolves at one end and $\mathrm{H}_{2}$ evolution takes place at the other end. As initially the amounts of metal ions and $\mathrm{H}_{2}$ in the solution are very tiny, taking the example of changing the concentration from 10 to $1 \mathrm{nM}$ requires very little charge in the end where metal dissolution takes place but shifts the Fermi level of the metal ion/metal couple $\sim 60 / n \mathrm{mV}$ more negative, where $n$ is the number of electrons transferred in the electrodeposition of metal. Nevertheless, if initially there is a significant amount of the species of both of the redox couples present in solution, the opposite reactions will take place in both ends of the particle (i.e., metal deposition at one end and dissolution at the other end, as illustrated in Figure $5 \mathrm{c}, \mathrm{d}^{68}$ ). Due to the Fermi level gradient in the solution imposed by the Galvani potential gradient, it is also possible to have electronic conduction in the aqueous solution by electron hopping in a self-exchange reaction of the ox and red in solution. ${ }^{69}$ However, this effect becomes significant only with redox species of high self-exchange reaction rates in concentrated solutions ${ }^{70}$ (like in redox polymers ${ }^{71}$ ).

Fermi level equilibration and redox electrocatalysis can be also studied at liquid-liquid interfaces. In contrast to metal 
electrodes, liquid-liquid interfaces are inherently defect-free and mechanically flexible and in some cases also selfhealing. ${ }^{72-75}$ In many cases, two-dimensional ordered films of molecules, ${ }^{76,77} \mathrm{NPs},{ }^{78-80}$ or microparticles ${ }^{81}$ can be relatively easily formed at liquid-liquid interfaces. ${ }^{82}$ Hence, electrochemistry at liquid-liquid interfaces has several advantages in comparison with electrochemical studies on regular electrodes: (i) studying the electrocatalytic activity of catalysts without the interference from the support and (ii) changing the Galvani potential difference between the two phases. The latter actually enables us to change the difference of the Fermi levels of the redox couples, that is, we can control the rate and direction of the electron transfer between two redox species in the different phases. $^{83}$ This advantage was illustrated by constructing a battery with a $\sim 0.8 \mathrm{~V}$ potential difference with the same redox couples in the positive and negative electrodes. ${ }^{84}$

\section{Electrochemistry at liquid-liquid interfaces has several advantages in comparison with electrochem- ical studies on regular electrodes: (i) studying the electrocatalytic activity of catalysts without the interference from the support and (ii) changing the Galvani potential difference between the two phases.}

Let us consider a reaction at equilibrium between an aqueous redox couple $\mathrm{O}_{1} / \mathrm{R}_{1}$ and the other redox couple $\mathrm{O}_{2} / \mathrm{R}_{2}$ dissolved in the organic phase

$$
\mathrm{O}_{1}^{\mathrm{aq}}+\mathrm{R}_{2}^{\circ} \rightleftharpoons \mathrm{R}_{1}^{\mathrm{aq}}+\mathrm{O}_{2}^{\circ}
$$

At equilibrium, the electrochemical potentials are equal, and we can obtain the expression for the Galvani potential difference

$$
\begin{aligned}
\tilde{\mu}_{\mathrm{O}_{1}^{\mathrm{aq}}} & +\tilde{\mu}_{\mathrm{R}_{2}^{\circ}}=\tilde{\mu}_{\mathrm{R}_{1}^{\mathrm{aq}}}+\tilde{\mu}_{\mathrm{O}_{2}^{\circ}} \\
\Delta_{\mathrm{o}}^{\mathrm{w}} \phi & =\left(\mu_{\mathrm{R}_{1}^{\mathrm{aq}}}-\mu_{\mathrm{O}_{1}^{\mathrm{aq}}}-\mu_{\mathrm{R}_{2}^{\circ}}+\mu_{\mathrm{O}_{2}^{\circ}}\right) / F \\
& =\left[E_{\mathrm{O}_{2} / \mathrm{R}_{2}}\right]_{\mathrm{SHE}}^{\circ}-\left[E_{\mathrm{O}_{1} / \mathrm{R}_{1}}\right]_{\mathrm{SHE}}^{\mathrm{aq}}
\end{aligned}
$$

The advantage of applying electrochemistry at liquid-liquid interfaces for studying NP electrocatalysis is now apparent; for a typical electrode reaction, there are only two adjustable parameters, the electrode potential and concentration ratio, but for electron-transfer reactions at liquid-liquid interfaces, we have three parameters that we can vary, $\Delta_{\mathrm{o}}^{\mathrm{w}} \phi$, the ratio of $\left[\mathrm{O}_{2}^{\circ}\right] /$ $\left[\mathrm{R}_{2}^{\circ}\right]$, and the ratio of $\left[\mathrm{O}_{1}^{\mathrm{aq}}\right] /\left[\mathrm{R}_{1}^{\mathrm{aq}}\right] .{ }^{9}$. When there is no Galvani potential difference, the redox potentials of redox couples in each phase will equilibrate so that $\left[E_{\mathrm{O}_{2} / \mathrm{R}_{2}}\right]_{\mathrm{SHE}}^{\circ}=\left[E_{\mathrm{O}_{1} / \mathrm{R}_{1}}\right]_{\mathrm{SHE}}^{\mathrm{aq}}$; otherwise, $\left[E_{\mathrm{O}_{2} / \mathrm{R}_{2}}\right]_{\mathrm{SHE}}^{\circ}=\left[E_{\mathrm{O}_{1} / \mathrm{R}_{1}}\right]_{\mathrm{SHE}}^{\mathrm{ag}}+\Delta_{\mathrm{o}}^{\mathrm{w}} \phi{ }^{9}$

Now, the Fermi level of the aqueous redox couple can be changed with respect to the organic redox couple simply by changing the Galvani potential difference, inducing electron transfer until the equilibrium is reached. For example, we have recently demonstrated $\mathrm{Au} \mathrm{NP}$-catalyzed reversible electron transfer between ferrocene and the aqueous $\left[\mathrm{Fe}(\mathrm{CN})_{6}\right]^{3-/ 4-}$ redox couple ${ }^{9}$ and irreversible oxygen reduction by decamethylferrocene $(\mathrm{DMFc}){ }^{10}$ Reaction 6 can take place either heterogeneously or homogeneously (by partition of one reactant into the other phase and ion transfer of the product back to the original phase), but this does not change the thermodynamics of the system. ${ }^{85}$

The Galvani potential difference can be adjusted both by an external power supply and with chemical polarization through introducing a common ion in both phases. In so-called "shakeflask" experiments, in which two immiscible phases are put in contact and stirred vigorously, both phases contain a common ion and the distribution of this ion polarizes the interface to a fixed value. ${ }^{86}$ Such chemical polarization along the two phases induces charge transfer across the interface and turns it into a platform for multielectron redox reactions like reduction of $\mathrm{O}_{2}$ and evolution of $\mathrm{H}_{2}{ }^{87-90}$ Redox catalysis and redox electrocatalysis at the ITIES has been recently reviewed; ${ }^{91,92}$ therefore, only some examples and recent developments will be considered in this Perspective.

From the point of view of practical applications, oxygen reduction is one of the most important energy-related reactions as it is one of the reactions of crucial importance for the hydrogen economy (oxygen reduction it is the limiting reaction in fuel cells, and efficient fuel cells are a requirement for the hydrogen economy), and it is an important reaction in energy conversion within our body. Due to the biomimetic nature of a liquid-liquid interface (a cell membrane may be described as two back-to-back liquid-liquid interfaces), oxygen reduction has been studied at these conditions by a number of catalysts and electron donors. ${ }^{87-90}$ In the absence of any catalyst, the reaction in the organic phase can be considered as an electrochemical chemical (EC or following reaction) type reaction where protons (or hydrated cations ${ }^{93}$ ) transfer into the organic phase in the electrochemical step, followed by homogeneous chemical reactions in the organic phase to result in oxygen reduction. ${ }^{94-96}$ When a molecular catalyst is employed, the chemical reactions in the organic phase can be considered to take place by redox catalysis, and apparent rates of these catalysts have been summarized recently by $\mathrm{Su}$ et al. ${ }^{97}$ However, if the catalyst is a conductive particle, ${ }^{10,98-101}$ oxygen reduction takes place via redox electrocatalysis. At the ITIES, both heterogeneous monophasic (electrochemical reactions taking place at the particle surface only in either the aqueous or organic phase) and heterogeneous biphasic (electrochemical reactions taking place at the particle surface in both the aqueous and organic phases, as in eq 6 and in Figure 6a) reactions are possible.

For example, the biphasic reduction of aqueous protons to $\mathrm{H}_{2}$ gas under anaerobic conditions by the highly lipophilic electron donor DMFc may be catalyzed by in situ-generated $\mathrm{Pt}$ and Pd NPs, ${ }^{102}$ as shown photographically and schematically in Figure 6 b,c. Inspired by this study, a series of non-noble, earthabundant $\mathrm{MoS}_{2}$-based catalysts was investigated at the ITIES, highlighting the role of the support in optimizing the catalyst performance (Figure 6e). ${ }^{52,53}$ The redox electrocatalytic activity of $\mathrm{WS}_{2}$ microparticles and CoS NPs adsorbed at ITIES (free or supported on carbon nanotubes) on the HER with DMFc was studied by Alsan et al. ${ }^{103,104}$ Further work highlighting the importance of the catalyst-support interactions was done by investigating redox electrocatalytic HER on in situ-generated $\mathrm{Cu}$ NPs at the water-DCE interface by $\mathrm{DMFc}^{105}$ and extension of the work to study $\mathrm{Cu}$ NPs deposited on multiwall carbon nanotubes. ${ }^{106}$ Deposition of $\mathrm{Cu}$ NPs on multiwall carbon nanotubes again facilitates electron transfer between the components as well as avoiding aggregation of the NPs. ${ }^{106}$ 


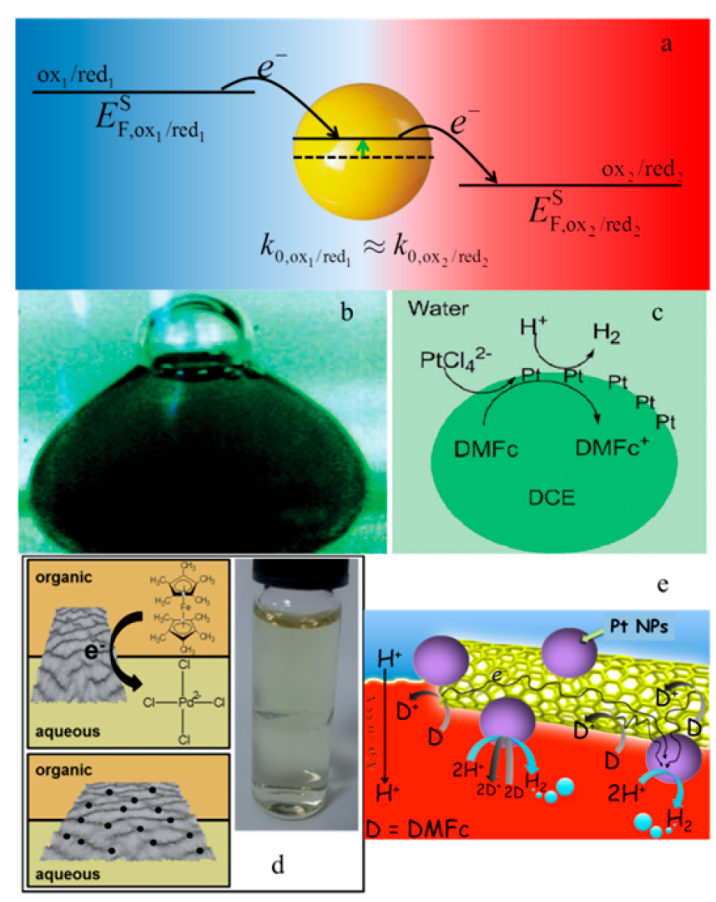

Figure 6. Examples of redox electrocatalysis at liquid-liquid interfaces. (a) Schematic of Fermi level equilibration and electron flows during redox electrocatalysis at polarized liquid-liquid interfaces with metallic NPs confined at the ITIES. (b) Photograph and (c) mechanism of the biphasic HER, whereby aqueous protons are reduced by lipophilic DMFc in the presence of in situ electrodeposited Pt NPs at a polarized liquid-liquid interface. (d) Schemes of $\mathrm{PdCl}_{4}{ }^{2-}$ reduction by DMFc via chemical vapor-deposited graphene (CVD GR) at the polarized liquid-liquid interface (above), forming the black dots marked Pd NPs (below), which are clearly visible in the photograph on the CVD GR floating at the polarized liquid-liquid interface. (e) Schematic of the biphasic HER in the presence of a preformed, conductive catalytic "Pt NPs on carbon nanotube" nanocomposite (Pt/CNT) floating at a polarized liquid-liquid interface. The electron donor, DMFc, may inject electrons anywhere on the carbon support, and these electrons are then efficiently shuttled along the conductive CNT electron "transport superhighway" to the Pt NP active sites where $\mathrm{H}_{2}$ evolution occurs. Alternatively, DMFc may directly inject electrons into Pt NPs on the CNT surface and cause $\mathrm{H}_{2}$ evolution to take place. Adapted from refs 54, 102, and 108 with permission from The Royal Society of Chemistry.

Additionally, redox electrocatalysis of the HER has been investigated on cubic and cubic-like $\mathrm{Cu}_{2} \mathrm{WS}_{4}$ nanomaterials, showing considerable enhancement of the HER catalytic activity by nearly 1000 -fold in comparison with noncatalyzed reactions. $^{107}$

It is also possible to both prepare and study high-surface-area supports functionalized by catalysts at the ITIES, and many approaches exist to create such hybrids. For example, in an extension of the work involving the nucleation and growth of freely diffusing metallic NPs at polarized liquid-liquid interfaces, Dryfe et al. recently introduced an elegant, controllable, and facile approach to create metallic NP/carbon support nanocomposites by assembling the carbon support (in this case, high-purity CVD GR) by transfer from poly(methyl methacrylate) at the polarized water-oil interface (Figure 6d). ${ }^{108}$ Metallic NPs were then deposited on the CVD GR by either spontaneous or electrochemically controlled biphasic processes. $^{108}$
Finally, liquid-liquid interfaces are a versatile platform to study photoinduced charge-transfer reactions for both redox electrocatalysis and for redox catalysis. For example, photoreduction of hexacyanoferrate by an electron donor in the organic phase was catalyzed by the self-assembled complex formed between the water-soluble porphyrins ZnTTPS and ZnTMPyP at ITIES. ${ }^{109}$ In this case, surface second harmonic generation $(\mathrm{SSHG})^{110}$ and time-resolved $\mathrm{SSHG}^{111}$ may provide detailed information on molecule configurations and positioning at the interface, whereas dynamics of photoresponses (kinetic constants of electron transfer) upon heterogeneous quenching at the ITIES can be probed by intensity modulated photocurrent spectroscopy (IMPS), as was shown for of ZnTPPC and ferrocene derivatives. ${ }^{112}$ Also, IMPS has been used recently to study the role of NPs as redox electrocatalysts in interfacial reaction between DMFc and water-soluble zwitterporphyrin (ZnDMPyDSPP). ${ }^{113}$ The authors demonstrated that the presence of gold NPs at ITIES negates kinetic limitation for the interfacial reactions, which corroborates with previous studies. ${ }^{9,85}$

An interesting new field is photoinduced redox electrocatalysis $^{114-116}$ and redox catalysis ${ }^{117,118}$ for synthesis of solar fuels. ${ }^{92}$ For example, $\mathrm{Cu}_{2} \mathrm{CoSnS}_{4}$ and $\mathrm{Cu}_{2} \mathrm{CoSnS}_{4}$ nanofibers have been suggested as candidates for photocatalytic HER. Indeed, they are alternative semiconductors with suitable band gaps (both around $1.5 \mathrm{eV}$ ), and their study revealed comparable $\mathrm{H}_{2}$ production rates to those of $\mathrm{Pt}$ particles. ${ }^{119}$

Redox electrocatalysis is useful to
study reactivity of particles with
and without supports, something
that traditional electrocatalysis is
not able to do, and the difficulty
controlling reaction rates can be
overcome by varying the initial
concentration ranges of the par-
ticipating species.

This Perspective shows that redox electrocatalysis is useful to study reactivity of particles with and without supports, something that traditional electrocatalysis is not able to do. However, it is more difficult to control the reaction rates in redox electrocatalysis. This problem may be overcome by varying the initial concentration ratios of the participating species. Nevertheless, more control can be obtained with bipolar electrochemistry or by employing electrochemistry at liquid-liquid interfaces. In the two former cases, additional methods (for example, spectroscopic techniques) are required to follow the reaction rates, while redox electrocatalysis at liquid-liquid interfaces allows direct measurement of the electric current corresponding to electron-transfer reactions. Additionally, very large electric fields are required to study reactions at NPs in bipolar conditions. As interactions between catalytic particles and the supporting material are receiving more and more interest, ${ }^{120,121}$ these approaches are expected to be implemented to study these effects in detail. Additionally, methods based on scanning electrochemical probe techniques are envisaged to study redox electrocatalysis locally and for photoinduced reactions, as recently demonstrated by Rastgar et al. $^{116}$ 


\section{AUTHOR INFORMATION}

\section{Corresponding Authors}

*E-mail: pekka.peljo@epfl.ch (P.P.).

*E-mail: hubert.girault@epfl.ch (H.H.G.).

\section{ORCID $\odot$}

Pekka Peljo: 0000-0002-1229-2261

Micheál D. Scanlon: 0000-0001-7951-7085

Astrid J. Olaya: 0000-0002-9770-130X

Lucie Rivier: 0000-0002-3795-3492

Evgeny Smirnov: 0000-0001-7930-7758

Hubert H. Girault: 0000-0001-5573-5774

Notes

The authors declare no competing financial interest.

\section{ACKNOWLEDGMENTS}

We acknowledge financial support from the Swiss National Science Foundation (Grants Ambizione Energy 160553 and Solar Fuels 2000-20_152 557/1). This publication has emanated from research by M.D.S., supported in part by a research grant from Science Foundation Ireland (SFI) under Grant Number 13/SIRG/2137.

\section{REFERENCES}

(1) Herranz, J.; Durst, J.; Fabbri, E.; Patru, A.; Cheng, X.; Permyakova, A. A.; Schmidt, T. J. Interfacial Effects on the Catalysis of the Hydrogen Evolution, Oxygen Evolution and CO2-Reduction Reactions for (Co-)Electrolyzer Development. Nano Energy 2016, 29, 4-28.

(2) Stamenkovic, V. R.; Strmcnik, D.; Lopes, P. P.; Markovic, N. M. Energy and Fuels from Electrochemical Interfaces. Nat. Mater. 2016, 16 (1), 57-69.

(3) Larcher, D.; Tarascon, J.-M. Towards Greener and More Sustainable Batteries for Electrical Energy Storage. Nat. Chem. 2014, 7 (1), 19-29.

(4) Strmcnik, D.; Lopes, P. P.; Genorio, B.; Stamenkovic, V. R.; Markovic, N. M. Design Principles for Hydrogen Evolution Reaction Catalyst Materials. Nano Energy 2016, 29, 29-36.

(5) Więckowski, A.; Savinova, E. R.; Vayenas, C. G. Catalysis and Electrocatalysis at Nanoparticle Surfaces; Marcel Dekker, 2003.

(6) Calle-Vallejo, F.; Pohl, M.; Reinisch, D.; Loffreda, D.; Sautet, P.; Bandarenka, A. Why Conclusions from Platinum Model Surfaces Do Not Necessarily Lead to Enhanced Nanoparticle Catalysts for the Oxygen Reduction Reaction. Chem. Sci. 2017, 8 (3), 2283-2289.

(7) O'Mullane, A. P. From Single Crystal Surfaces to Single Atoms: Investigating Active Sites in Electrocatalysis. Nanoscale 2014, 6 (8), 4012.

(8) Scanlon, M. D.; Peljo, P.; Méndez, M. A.; Smirnov, E.; Girault, H. $\mathrm{H}$. Charging and Discharging at the Nanoscale: Fermi Level Equilibration of Metallic Nanoparticles. Chem. Sci. 2015, 6 (5), $2705-2720$.

(9) Smirnov, E.; Peljo, P.; Scanlon, M. D.; Girault, H. H. Interfacial Redox Catalysis on Gold Nanofilms at Soft Interfaces. ACS Nano 2015, 9 (6), 6565-6575.

(10) Smirnov, E.; Peljo, P.; Scanlon, M. D.; Girault, H. H. Gold Nanofilm Redox Catalysis for Oxygen Reduction at Soft Interfaces. Electrochim. Acta 2016, 197, 362-373.

(11) Holmberg, N.; Laasonen, K.; Peljo, P. Charge Distribution and Fermi Level in Bimetallic Nanoparticles. Phys. Chem. Chem. Phys. 2016, 18 (4), 2924-2931.

(12) Peljo, P.; Manzanares, J. A.; Girault, H. H. Contact Potentials, Fermi Level Equilibration, and Surface Charging. Langmuir 2016, 32 (23), 5765-5775.

(13) Girault, H. H. Analytical and Physical Electrochemistry; EPFL Press: Lausanne, 2004.
(14) Reiss, H. The Fermi Level and the Redox Potential. J. Phys. Chem. 1985, 89 (18), 3783-3791.

(15) Masa, J.; Schuhmann, W. Electrocatalysis and Bioelectrocatalysis - Distinction without a Difference. Nano Energy 2016, 29, 466-475.

(16) Alivisatos, A. P. Semiconductor Clusters, Nanocrystals, and Quantm Dots. Science 1996, 271, 933-937.

(17) Kamat, P. V. Quantum Dot Solar Cells. The Next Big Thing in Photovoltaics. J. Phys. Chem. Lett. 2013, 4 (6), 908-918.

(18) Shirasaki, Y.; Supran, G. J.; Bawendi, M. G.; Bulovic, V. Emergence of Colloidal Quantum-Dot Light-Emitting Technologies. Nat. Photonics 2012, 7 (1), 13-23.

(19) Amstutz, V.; Toghill, K. E.; Powlesland, F.; Vrubel, H.; Comninellis, C.; Hu, X.; Girault, H. H. Renewable Hydrogen Generation from a Dual-Circuit Redox Flow Battery. Energy Environ. Sci. 2014, 7 (7), 2350-2358.

(20) Dennison, C. R.; Vrubel, H.; Amstutz, V.; Peljo, P.; Toghill, K. E.; Girault, H. H. Redox Flow Batteries, Hydrogen and Distributed Storage. Chimia 2015, 69 (12), 753-758.

(21) Peljo, P.; Vrubel, H.; Amstutz, V.; Pandard, J.; Morgado, J.; Santasalo-Aarnio, A.; Lloyd, D.; Gumy, F.; Dennison, C. R.; Toghill, K. E.; et al. All-Vanadium Dual Circuit Redox Flow Battery for Renewable Hydrogen Generation and Desulfurisation. Green Chem. 2016, 18 (6), 1785-1797.

(22) Spiro, M. Heterogeneous Catalysis in Solution. Part 17.-Kinetics of Oxidation-Reduction Reaction Catalysed by Electron Transfer through the Solid: An Electrochemical Treatment. J. Chem. Soc., Faraday Trans. 1 1979, 75, 1507-1512.

(23) Miller, D. S.; Bard, A. J.; McLendon, G.; Ferguson, J. Catalytic Water Reduction at Colloidal Metal "microelectrodes". 2. Theory and Experiment. J. Am. Chem. Soc. 1981, 103 (18), 5336-5341.

(24) Wagner, C.; Traud, W. On the Interpretation of Corrosion Processes through the Superposition of Electrochemical Partial Processes and on the Potential of Mixed Electrodes," with a Perspective by F. Mansfeld. Corrosion 2006, 62 (10), 843-855.

(25) Wagner, C.; Traud, W. Über Die Deutung von Korrosionsvorgängen Durch Überlagerung von Elektrochemischen Teilvorgängen Und Über Die Potentialbildung an Mischelektroden. Z. Elektrochem. 1938, 44 (7), 391-402.

(26) Zelinsky, A. G.; Pirogov, B. Y.; Yurjev, O. A. Open Circuit Potential Transients and Electrochemical Quartz Crystal Microgravimetry Measurements of Dissolution of Copper in Acidic Sulfate Solutions. Corros. Sci. 2004, 46 (5), 1083-1093.

(27) Ohno, I. Electrochemistry of Electroless Plating. Mater. Sci. Eng., A 1991, 146 (1-2), 33-49.

(28) Henglein, A. Reactions of Organic Free Radicals at Colloidal Silver in Aqueous Solution. Electron Pool Effect and Water Decomposition. J. Phys. Chem. 1979, 83 (17), 2209-2216.

(29) Matheson, M. S.; Lee, P. C.; Meisel, D.; Pelizzetti, E. Kinetics of Hydrogen Production from Methyl Viologen Radicals on Colloidal Platinum. J. Phys. Chem. 1983, 87 (3), 394-399.

(30) Grätzel, C. K.; Grätzel, M. Hydrogen Evolution from the Photolysis of Alcoholic Benzophenone Solutions via Redox Catalysis. J. Am. Chem. Soc. 1979, 101 (26), 7741-7743.

(31) Kiwi, J.; Grätzel, M. Projection, Size Factors, and Reaction Dynamics of Colloidal Redox Catalysts Mediating Light Induced Hydrogen Evolution from Water. J. Am. Chem. Soc. 1979, 101 (24), 7214-7217.

(32) Miller, D. S.; McLendon, G. Quantitative Electrochemical Kinetics Studies Of "microelectrodes": Catalytic Water Reduction by Methyl Viologen/colloidal Platinum. J. Am. Chem. Soc. 1981, 103 (23), 6791-6796.

(33) Venturi, M.; Mulazzani, Q. G.; Hoffman, M. Z. Radiolytically Induced One-Electron Reduction of Methylviologen in Aqueous Solution. Platinum-Catalyzed Formation of Dihydrogen. J. Phys. Chem. 1984, 88 (5), 912-918.

(34) Henglein, A. Catalysis of Hydrogen Formation from an Organic Radical in Aqueous Solutions by Colloidal Silver. Angew. Chem., Int. Ed. Engl. 1979, 18 (5), 418. 
(35) Henglein, A.; Lilie, J. Storage of Electrons in Aqueous Solution: The Rates of Chemical Charging and Discharging the Colloidal Silver Microelectrode. J. Am. Chem. Soc. 1981, 103 (5), 1059-1066.

(36) Henglein, A.; Lindig, B.; Westerhausen, J. Photochemical Electron Storage on Colloidal Metals and Hydrogen Formation by Free Radicals. J. Phys. Chem. 1981, 85 (12), 1627-1628.

(37) Meisel, D. Catalysis of Hydrogen Production in Irradiated Aqueous Solutions by Gold Sols. J. Am. Chem. Soc. 1979, 101 (20), 6133-6135.

(38) Kopple, K.; Meyerstein, D.; Meisel, D. Mechanism of the Catalytic Hydrogen Production by Gold Sols. Hydrogen/deuterium Isotope Effect Studies. J. Phys. Chem. 1980, 84 (8), 870-875.

(39) Meisel, D.; Mulac, W. A.; Matheson, M. S. Catalysis of Methyl Viologen Radical Reactions by Polymer-Stabilized Gold Sols. J. Phys. Chem. 1981, 85 (2), 179-187.

(40) Henglein, A. Small-Particle Research: Physicochemical Properties of Extremely Small Colloidal Metal and Semiconductor Particles. Chem. Rev. 1989, 89 (8), 1861-1873.

(41) Henglein, A. Physicochemical Properties of Small Metal Particles in Solution: "microelectrode" reactions, Chemisorption, Composite Metal Particles, and the Atom-to-Metal Transition. J. Phys. Chem. 1993, 97 (21), 5457-5471.

(42) Henglein, A. Catalysis of the Reduction of thallium(1+) and of Dichloromethane by Colloidal Silver in Aqueous Solution. J. Phys. Chem. 1979, 83 (22), 2858-2862.

(43) Henglein, A. Colloidal Silver Catalyzed Multi-Electron Transfer Processes in Aqueous Solution. Ber. Der Bunsenges. Phys. Chem. 1980, 84 (3), 253-259.

(44) Henglein, A.; Mulvaney, P.; Linnert, T.; Holzwarth, A. Surface Chemistry of Colloidal Silver: Reduction of Adsorbed cadmium(2+) Ions and Accompanying Optical Effects. J. Phys. Chem. 1992, 96 (6), 2411-2414.

(45) Henglein, A.; Mulvaney, P.; Holzwarth, A.; Sosebee, T. E.; Fojtik, A. Electrochemistry of Colloidal Silver Particles in Aqueous Solution: Deposition of Lead and Indium and Accompanying Optical Effects. Ber. Der Bunsenges. Phys. Chem. 1992, 96 (6), 754-759.

(46) Mulvaney, P.; Giersig, M.; Henglein, A. Electrochemistry of Multilayer Colloids: Preparation and Absorption Spectrum of GoldCoated Silver Particles. J. Phys. Chem. 1993, 97 (27), 7061-7064.

(47) Katsikas, L.; Gutiérrez, M.; Henglein, A. Bimetallic Colloids: Silver and Mercury. J. Phys. Chem. 1996, 100 (27), 11203-11206.

(48) Henglein, A.; Brancewicz, C. Absorption Spectra and Reactions of Colloidal Bimetallic Nanoparticles Containing Mercury. Chem. Mater. 1997, 9 (10), 2164-2167.

(49) Henglein, A.; Giersig, M. Radiolytic Formation of Colloidal Tin and Tin-Gold Particles in Aqueous Solution. J. Phys. Chem. 1994, 98 (28), 6931-6935.

(50) Henglein, F.; Henglein, A.; Mulvaney, P. Surface Chemistry of Colloidal Gold: Deposition and Reoxidation of $\mathrm{Pb}, \mathrm{Cd}$, and Tl. Ber. Der Bunsenges. Phys. Chem. 1994, 98 (2), 180-189.

(51) Mulvaney, P.; Giersig, M.; Henglein, A. Surface Chemistry of Colloidal Gold: Deposition of Lead and Accompanying Optical Effects. J. Phys. Chem. 1992, 96 (25), 10419-10424.

(52) Hatay, I.; Ge, P. Y.; Vrubel, H.; Hu, X.; Girault, H. H. Hydrogen Evolution at Polarised Liquid/liquid Interfaces Catalyzed by Molybdenum Disulfide. Energy Environ. Sci. 2011, 4 (10), 4246-4251.

(53) Ge, P.; Scanlon, M. D.; Peljo, P.; Bian, X.; Vubrel, H.; O’Neill, A.; Coleman, J. N.; Cantoni, M.; Hu, X.; Kontturi, K.; et al. Hydrogen Evolution across Nano-Schottky Junctions at Carbon Supported MoS 2 Catalysts in Biphasic Liquid Systems. Chem. Commun. 2012, 48 (52), 6484-6486.

(54) Bian, X.; Scanlon, M. D.; Wang, S.; Liao, L.; Tang, Y.; Liu, B.; Girault, H. H. Floating Conductive Catalytic Nano-Rafts at Soft Interfaces for Hydrogen Evolution. Chem. Sci. 2013, 4 (9), 34323441.

(55) Wang, Y.; Shan, X.; Tao, N. Emerging Tools for Studying Single Entity Electrochemistry. Faraday Discuss. 2016, 193, 9-39.
(56) Sokolov, S. V.; Eloul, S.; Kätelhön, E.; Batchelor-McAuley, C.; Compton, R. G. Electrode-particle Impacts: A Users Guide. Phys. Chem. Chem. Phys. 2017, 19 (1), 28-43.

(57) Mirkin, M. V.; Sun, T.; Yu, Y.; Zhou, M. Electrochemistry at One Nanoparticle. Acc. Chem. Res. 2016, 49 (10), 2328-2335.

(58) Brasiliense, V.; Berto, P.; Combellas, C.; Tessier, G.; Kanoufi, F. Electrochemistry of Single Nanodomains Revealed by Three-Dimensional Holographic Microscopy. Acc. Chem. Res. 2016, 49 (9), 20492057.

(59) Chen, C.-H.; Ravenhill, E. R.; Momotenko, D.; Kim, Y.-R.; Lai, S. C. S.; Unwin, P. R. Impact of Surface Chemistry on NanoparticleElectrode Interactions in the Electrochemical Detection of Nanoparticle Collisions. Langmuir 2015, 31 (43), 11932-11942.

(60) Novo, C.; Funston, A. M.; Mulvaney, P. Direct Observation of Chemical Reactions on Single Gold Nanocrystals Using Surface Plasmon Spectroscopy. Nat. Nanotechnol. 2008, 3 (10), 598-602.

(61) Novo, C.; Funston, A. M.; Gooding, A. K.; Mulvaney, P. Electrochemical Charging of Single Gold Nanorods. J. Am. Chem. Soc. 2009, 131 (41), 14664-14666.

(62) Bartlett, T. R.; Sokolov, S. V.; Compton, R. G. Electrochemical Nanoparticle Sizing Via Nano-Impacts: How Large a Nanoparticle Can Be Measured? ChemistryOpen 2015, 4 (5), 600-605.

(63) Peljo, P.; Manzanares, J. A.; Girault, H. H. Variation of the Fermi level and the electrostatic force of a metallic nanoparticle upon colliding with an electrode. Chem. Sci. 2017, 8, 4795-4803.

(64) Koefoed, L.; Pedersen, S. U.; Daasbjerg, K. Bipolar electrochemistry-A Wireless Approach for Electrode Reactions. Curr. Opin. Electrochem. 2017, 2, 13.

(65) Fosdick, S. E.; Knust, K. N.; Scida, K.; Crooks, R. M. Bipolar Electrochemistry. Angew. Chem., Int. Ed. 2013, 52 (40), 10438-10456.

(66) Sarkar, S.; Lai, S.; Lemay, S. Unconventional Electrochemistry in Micro-/Nanofluidic Systems. Micromachines 2016, 7 (5), 81.

(67) Bradley, J.-C.; Chen, H.-M.; Crawford, J.; Eckert, J.; Ernazarova, K.; Kurzeja, T.; Lin, M.; McGee, M.; Nadler, W.; Stephens, S. G. Creating Electrical Contacts between Metal Particles Using Directed Electrochemical Growth. Nature 1997, 389 (6648), 268-271.

(68) Loget, G.; Kuhn, A. Electric Field-Induced Chemical Locomotion of Conducting Objects. Nat. Commun. 2011, 2, 535.

(69) Dahms, H. Electronic Conduction in Aqueous Solution. J. Phys. Chem. 1968, 72 (1), 362-364.

(70) Ruff, I.; Friedrich, V. J. Transfer Diffusion. I. Theoretical. J. Phys. Chem. 1971, 75 (21), 3297-3302.

(71) Buttry, D. A.; Anson, F. C. Electron Hopping vs. Molecular Diffusion as Charge Transfer Mechanisms in Redox Polymer Films. J. Electroanal. Chem. Interfacial Electrochem. 1981, 130, 333-338.

(72) Binder, W. H. Supramolecular Assembly of Nanoparticles at Liquid-Liquid Interfaces. Angew. Chem., Int. Ed. 2005, 44 (33), 51725175.

(73) Edel, J. B.; Kornyshev, A. A.; Urbakh, M. Self-Assembly of Nanoparticle Arrays for Use as Mirrors, Sensors, and Antennas. ACS Nano 2013, 7 (11), 9526-9532.

(74) Edel, J. B.; Kornyshev, A. A.; Kucernak, A. R.; Urbakh, M. Fundamentals and Applications of Self-Assembled Plasmonic Nanoparticles at Interfaces. Chem. Soc. Rev. 2016, 45 (6), 1581-1596.

(75) Böker, A.; He, J.; Emrick, T.; Russell, T. P. Self-Assembly of Nanoparticles at Interfaces. Soft Matter 2007, 3 (10), 1231.

(76) Olaya, A. J.; Schaming, D.; Brevet, P.-F.; Nagatani, H.; Zimmermann, T.; Vanicek, J.; Xu, H.-J.; Gros, C. P.; Barbe, J.-M.; Girault, H. H. Self-Assembled Molecular Rafts at LiquidlLiquid Interfaces for Four-Electron Oxygen Reduction. J. Am. Chem. Soc. 2012, 134 (1), 498-506.

(77) Olaya, A. J.; Schaming, D.; Brevet, P. F.; Nagatani, H.; Xu, H. J.; Meyer, M.; Girault, H. H. Interfacial Self-Assembly of Water-Soluble Cationic Porphyrins for the Reduction of Oxygen to Water. Angew. Chem., Int. Ed. 2012, 51 (26), 6447-6451.

(78) Reincke, F.; Hickey, S. G.; Kegel, W. K.; Vanmaekelbergh, D. Spontaneous Assembly of a Monolayer of Charged Gold Nanocrystals at the Water/oil Interface. Angew. Chem., Int. Ed. 2004, 43 (4), 458462. 
(79) Smirnov, E.; Scanlon, M. D.; Momotenko, D.; Vrubel, H.; Méndez, M. A.; Brevet, P.-F.; Girault, H. H. Gold Metal Liquid-Like Droplets. ACS Nano 2014, 8 (9), 9471-9481.

(80) Fang, P.-P.; Chen, S.; Deng, H.; Scanlon, M. D.; Gumy, F.; Lee, H. J.; Momotenko, D.; Amstutz, V.; Cortés-Salazar, F.; Pereira, C. M.; et al. Conductive Gold Nanoparticle Mirrors at Liquid/Liquid Interfaces. ACS Nano 2013, 7 (10), 9241-9248.

(81) Bormashenko, E. Liquid Marbles: Properties and Applications. Curr. Opin. Colloid Interface Sci. 2011, 16 (4), 266-271.

(82) Booth, S. G.; Dryfe, R. A. W. Assembly of Nanoscale Objects at the Liquid/Liquid Interface. J. Phys. Chem. C 2015, 119 (41), 2329523309.

(83) Smirnov, E.; Peljo, P.; Scanlon, M. D.; Girault, H. H. Interfacial Redox Catalysis on Gold Nanofilms at Soft Interfaces. ACS Nano 2015, 9 (6), 6565-6575.

(84) Peljo, P.; Bichon, M.; Girault, H. H. Ion Transfer Battery: Storing Energy by Transferring Ions across Liquid-liquid Interfaces. Chem. Commun. 2016, 52 (63), 9761-9764.

(85) Peljo, P.; Smirnov, E.; Girault, H. H. Heterogeneous versus Homogeneous Electron Transfer Reactions at Liquid-liquid Interfaces: The Wrong Question? J. Electroanal. Chem. 2016, 779, 187-198.

(86) Peljo, P.; Qiao, L.; Murtomäki, L.; Johans, C.; Girault, H. H.; Kontturi, K. Electrochemically Controlled Proton-Transfer-Catalyzed Reactions at Liquid-Liquid Interfaces: Nucleophilic Substitution on Ferrocene Methanol. ChemPhysChem 2013, 14 (2), 311-314.

(87) Peljo, P.; Murtomäki, L.; Kallio, T.; Xu, X.-J.; Meyer, M.; Gros, C. P.; Barbe, J. M.; Girault, H. H.; Laasonen, K.; Kontturi, K. Biomimetic Oxygen Reduction by Cofacial Porphyrins at a LiquidLiquid Interface. J. Am. Chem. Soc. 2012, 134 (13), 5974-5984.

(88) Mendez, M. A.; Partovi-Nia, R.; Hatay, I.; Su, B.; Ge, P.; Olaya, A.; Younan, N.; Hojeij, M.; Girault, H. H. Molecular Electrocatalysis at Soft Interfaces. Phys. Chem. Chem. Phys. 2010, 12 (46), 15163-15171.

(89) Hatay, I.; Su, B.; Li, F.; Méndez, M. A.; Khoury, T.; Gros, C. P.; Barbe, J. M.; Ersoz, M.; Samec, Z.; Girault, H. H. Proton-Coupled Oxygen Reduction at Liquid-Liquid Interfaces Catalyzed by Cobalt Porphine. J. Am. Chem. Soc. 2009, 131 (37), 13453-13459.

(90) Deng, H.; Peljo, P.; Cortés-Salazar, F.; Ge, P.; Kontturi, K.; Girault, H. H. Oxygen and Hydrogen Peroxide Reduction by 1,2Diferrocenylethane at a Liquid/liquid Interface. J. Electroanal. Chem. 2012, 681, 16-23.

(91) Rodgers, A. N. J.; Booth, S. G.; Dryfe, R. A. W. Particle Deposition and Catalysis at the Interface between Two Immiscible Electrolyte Solutions (ITIES): A Mini-Review. Electrochem. Commun. 2014, 47, 17-20.

(92) Girault, H. H. Hard Science at Soft Interfaces. In Developments in Electrochemistry: Science Inspired by Martin Fleischmann; Pletcher, D., Tian, Z.-Q., Williams, D. E., Eds.; John Wiley \& Sons, Ltd.: Chichester, U.K., 2014; pp 295-308.

(93) Deng, H.; Peljo, P.; Stockmann, T. J.; Qiao, L.; Vainikka, T.; Kontturi, K.; Opallo, M.; Girault, H. H. Surprising Acidity of Hydrated Lithium Cations in Organic Solvents. Chem. Commun. 2014, 50 (42), 5554-5557.

(94) Stockmann, T. J.; Deng, H.; Peljo, P.; Kontturi, K.; Opallo, M.; Girault, H. H. Mechanism of Oxygen Reduction by Metallocenes near Liquidlliquid Interfaces. J. Electroanal. Chem. 2014, 729, 43-52.

(95) Deng, H.; Peljo, P.; Momotenko, D.; Cortés-Salazar, F.; Stockmann, T. J.; Kontturi, K.; Opallo, M.; Girault, H. H. Kinetic Differentiation of Bulk/interfacial Oxygen Reduction Mechanisms at/ near Liquid/Liquid Interfaces Using Scanning Electrochemical Microscopy. J. Electroanal. Chem. 2014, 732, 101-109.

(96) Deng, H.; Stockmann, T. J.; Peljo, P.; Opallo, M.; Girault, H. H. Electrochemical Oxygen Reduction at Soft Interfaces Catalyzed by the Transfer of Hydrated Lithium Cations. J. Electroanal. Chem. 2014, 731, $28-35$.

(97) Xuan, Y.; Xie, L.; Huang, X.; Su, B. Molecular Electrocatalysis of Oxygen Reduction by iron(II) Phthalocyanine at the Liquid/liquid Interface. J. Electroanal. Chem. 2016, 766, 37-43.

(98) Rastgar, S.; Deng, H.; Cortés-Salazar, F.; Scanlon, M. D.; Pribil, M.; Amstutz, V.; Karyakin, A. A.; Shahrokhian, S.; Girault, H. H.
Oxygen Reduction at Soft Interfaces Catalyzed by In Situ-Generated Reduced Graphene Oxide. ChemElectroChem 2014, 1 (1), 59-63.

(99) Rodgers, A. N. J.; Dryfe, R. A. W. Oxygen Reduction at the Liquid-Liquid Interface: Bipolar Electrochemistry through Adsorbed Graphene Layers. ChemElectroChem 2016, 3 (3), 472-479.

(100) Jedraszko, J.; Nogala, W.; Adamiak, W.; Dongmo, S.; Wittstock, G.; Girault, H. H.; Opallo, M. Catalysis at the Room Temperature Ionic Liquidlwater Interface: $\mathrm{H}_{2} \mathrm{O}_{2}$ Generation. Chem. Commun. 2015, 51 (31), 6851-6853.

(101) Gründer, Y.; Fabian, M. D.; Booth, S. G.; Plana, D.; Fermín, D. J.; Hill, P. I.; Dryfe, R. A. W. Solids at the Liquid-liquid Interface: Electrocatalysis with Pre-Formed Nanoparticles. Electrochim. Acta 2013, 110 (0), 809-815.

(102) Nieminen, J. J.; Hatay, I.; Ge, P.-Y. P.; Méndez, M. A.; Murtomäki, L.; Girault, H. H. Hydrogen Evolution Catalyzed by Electrodeposited Nanoparticles at the Liquid/liquid Interface. Chem. Commun. 2011, 47 (19), 5548-5550.

(103) Aslan, E.; Akin, I.; Patir, I. H. Highly Active Cobalt Sulfide/ Carbon Nanotube Catalyst for Hydrogen Evolution at Soft Interfaces. Chem. - Eur. J. 2016, 22 (15), 5342-5349.

(104) Aslan, E.; Hatay Patir, I.; Ersoz, M. Catalytic Hydrogen Evolution by Tungsten Disulfide at Liquid-Liquid Interfaces. ChemCatChem 2014, 6 (10), 2832-2835.

(105) Aslan, E.; Patir, I. H.; Ersoz, M. Cu Nanoparticles Electrodeposited at Liquid-Liquid Interfaces: A Highly Efficient Catalyst for the Hydrogen Evolution Reaction. Chem. - Eur. J. 2015, 21 (12), 4585-4589.

(106) Aslan, E.; Akin, I.; Patir, I. H. Enhanced Hydrogen Evolution Catalysis Based on $\mathrm{Cu}$ Nanoparticles Deposited on Carbon Nanotubes at the Liquid/Liquid Interface. ChemCatChem 2016, 8 (4), 719-723.

(107) Ozel, F.; Aslan, E.; Sarilmaz, A.; Hatay Patir, I. Hydrogen Evolution Catalyzed by $\mathrm{Cu}_{2} \mathrm{WS}_{4}$ at Liquid-Liquid Interfaces. ACS Appl. Mater. Interfaces 2016, 8 (39), 25881-25887.

(108) Toth, P. S.; Ramasse, Q. M.; Velicky, M.; Dryfe, R. A. W. Functionalization of Graphene at the Organic/water Interface. Chem. Sci. 2015, 6, 1316.

(109) Fermín, D. J.; Duong, H. D.; Ding, Z.; Brevet, P. F.; Girault, H. H. Photoinduced Electron Transfer at Liquid/liquid Interfaces. Part III. Photoelectrochemical Responses Involving Porphyrin Ion Pairs. J. Am. Chem. Soc. 1999, 121 (43), 10203-10210.

(110) Nagatani, H.; Samec, Z.; Brevet, P. F.; Fermín, D. J.; Girault, H. $\mathrm{H}$. Adsorption and Aggregation of Meso-tetrakis(4-Carboxyphenyl)porphyrinato zinc(II) at the Polarized waterl1,2-Dichloroethane Interface. J. Phys. Chem. B 2003, 107 (3), 786-790.

(111) Olaya, A. J.; Brevet, P. F.; Smirnov, E. A.; Girault, H. H. Ultrafast Population Dynamics of Surface-Active Dyes during Electrochemically Controlled Ion Transfer across a Liquidlliquid Interface. J. Phys. Chem. C 2014, 118 (43), 25027-25031.

(112) Fermin, D. J.; Dung Duong, H.; Ding, Z.; Brevet, P. F.; Girault, H. H. Photoinduced Electron Transfer at Liquid/liquid Interfaces Part II. A Study of the Electron Transfer and Recombination Dynamics by Intensity Modulated Photocurrent Spectroscopy (IMPS). Phys. Chem. Chem. Phys. 1999, 1 (7), 1461-1467.

(113) Gschwend, G. C.; Smirnov, E.; Peljo, P.; Girault, H. Electrovariable Gold Nanoparticle Films at Liquid-Liquid Interfaces: From Redox Electrocatalysis to Marangoni-Shutters. Faraday Discuss. 2017, 199, 565-583.

(114) Plana, D.; Fermín, D. J. Photoelectrochemical Activity of Colloidal TiO2 Nanostructures Assembled at Polarisable Liquid/liquid Interfaces. J. Electroanal. Chem. 2016, 780, 373-378.

(115) Plana, D.; Bradley, K. A.; Tiwari, D.; Fermín, D. J. Over 75\% Incident-Photon-to-Current Efficiency without Solid Electrodes. Phys. Chem. Chem. Phys. 2016, 18 (18), 12428-12433.

(116) Rastgar, S.; Pilarski, M.; Wittstock, G. Polarized Liquid-Liquid Interface Meets Visible Light-Driven Catalytic Water Oxidation. Chem. Commun. 2016, 52 (76), 11382-11385.

(117) Rivier, L.; Stockmann, T. J.; Méndez, M. A.; Scanlon, M. D.; Peljo, P.; Opallo, M.; Girault, H. H. Decamethylruthenocene Hydride 
and Hydrogen Formation at LiquidlLiquid Interfaces. J. Phys. Chem. C 2015, 119 (46), 25761-25769.

(118) Rivier, L.; Peljo, P.; Vannay, L. A. C.; Gschwend, G. C.; Méndez, M. A.; Corminboeuf, C.; Scanlon, M. D.; Girault, H. H. Photoproduction of Hydrogen by Decamethylruthenocene Combined with Electrochemical Recycling. Angew. Chem., Int. Ed. 2017, 56 (9), 2324-2327.

(119) Ozel, F.; Yar, A.; Aslan, E.; Arkan, E.; Aljabour, A.; Can, M.; Patir, I. H.; Kus, M.; Ersoz, M. Earth-Abundant $\mathrm{Cu}_{2} \mathrm{CoSnS}_{4}$ Nanofibers for Highly Efficient $\mathrm{H}_{2}$ Evolution at Soft Interfaces. ChemNanoMat 2015, 1 (7), 477-481.

(120) Ostojic, N.; Thorpe, J. H.; Crooks, R. M. Electron Transfer Facilitated by Dendrimer-Encapsulated Pt Nanoparticles Across Ultrathin, Insulating Oxide Films. J. Am. Chem. Soc. 2016, 138 (21), 6829-6837.

(121) Ostojic, N.; Crooks, R. M. Electrocatalytic Reduction of Oxygen on Platinum Nanoparticles in the Presence and Absence of Interactions with the Electrode Surface. Langmuir 2016, 32 (38), 9727-9735. 